Biophysical Reviews and Letters

Vol. 10, No. 4 (2015) 257-258

(C) World Scientific Publishing Company

DOI: $10.1142 / \mathrm{S} 1793048015990015$

\title{
Author Index \\ Volume 10 (2015)
}

Antonyan, A. P., see Shahinyan, M. A.

$4(2015) 201$

Aruna, P., see Chinnathambi, S.

2 (2015) 115

Chaplain, M. A. J. \& Powathil, G. G., Multiscale Modelling of Cancer Progression and Treatment Control: The Role of Intracellular Heterogeneities in Chemotherapy Treatment

Chinnathambi, S., Karthikeyan, S., Velmurugan, D., Hanagata, N., Aruna, P. \& Ganesan, S., Investigations on the Interactions of 5-Fluorouracil with Herring Sperm DNA:

Steady State/Time Resolved and Molecular Modeling Studies

Flomenbom, O., The Society-Deciders Model and Fairness in

Nations

3 (2015) 157

Galich, N. E., Intermittency and Changing Stability of

Oxidative Activity of DNA in Chromosomes Inside Living

Cells for Medical Diagnostics

$4(2015) 187$

Ganesan, S., see Chinnathambi, S.

2 (2015) 115

Grigoryan, Z. A. \& Karapetian, A. T., Short Double Stranded

DNA Alignment in the Melt of Flexible Polymers

$1(2015) 59$

Hanagata, N., see Chinnathambi, S.

2 (2015) 115

Iomin, A., Continuous Time Random Walk and

Migration-Proliferation Dichotomy of Brain Cancer

Karapetian, A. T., see Grigoryan, Z. A.

$1(2015) 37$

$1(2015) 59$

2 (2015) 115

Kuncic, Z., Advances in Computational Radiation Biophysics for Cancer Therapy: Simulating Nano-Scale Damage by Low-Energy Electrons

$1(2015) 25$

Mierke, C. T., Physical View on the Interactions Between

Cancer Cells and the Endothelial Cell Lining During Cancer

Cell Transmigration and Invasion

$1(2015) 1$

Mikaelyan, M. S., see Shahinyan, M. A.

4 (2015) 201

Powathil, G. G., see Chaplain, M. A. J.

$2(2015) 97$

Romero, J. M. \& Trenado, C., Analytical Solution of a Tapering

Cable Equation for Dendrites and Conformal Symmetry

3 (2015) 175

Ryabov, A., Single-File System with Absorbing Boundary:

Tracer Dynamics and First-Passage Properties

$2(2015) 85$ 
Shahinyan, M. A., Antonyan, A. P., Mikaelyan, M. S. \& Vardevanyan, P. O., Study of influence of millimeter range electromagnetic waves on water-saline solutions of albumin

Shestopaloff, Y. K., Why Cells Grow and Divide? General

Growth Mechanism and How it Defines Cells' Growth,

Reproduction and Metabolic Properties

4 (2015) 209

Trenado, C., see Romero, J. M.

3 (2015) 175

Trusova, V. M., Protein Fibrillar Nanopolymers:

Molecular-Level Insights into Their Structural, Physical and Mechanical Properties

Vardevanyan, P. O., see Shahinyan, M. A.

4 (2015) 201

Velmurugan, D., see Chinnathambi, S.

2 (2015) 115

Zhdanov, V. P., Kinetics of Single-Enzyme Reactions on Vesicles: Role of Substrate Aggregation 